\title{
Antropologia dos museus: um campo de estudos em expansão
}

\section{Anthropology of museums: a field of studies in expansion}

Maria Eunice Maciel ${ }^{*}$

* Universidade Federal do Rio Grande do Sul - Porto Alegre, RS, Brasil mariaeunicemaciel@gmail.com

https://orcid.org/0000-0002-0000-1287

Regina Abreu**

** Universidade Federal do Estado do Rio de Janeiro - Rio de Janeiro, RJ, Brasil abreuregin@gmail.com

https://orcid.org/0000-0002-3880-1749 
A tristeza estampada no rosto de uma das mais antigas múmias egípcias que integrava o acervo do Museu Nacional e que escolhemos para a capa do número 53 de Horizontes Antropológicos expressa o sentimento de todos nós diante da tragédia ocorrida no dia 2 de setembro de 2018, quando um incêndio de enormes proporções destruiu parte expressiva do acervo e do próprio prédio do nosso mais antigo e importante museu, justamente quando festejava seus 200 anos de existência. Já estávamos em organização deste volume quando essa tragédia aconteceu e, assim, esta edição de Horizontes Antropológicos, dedicada à antropologia dos museus, também homenageia essa instituição, cujas exposições e acervos encantaram sucessivas gerações, tendo sido uma das primeiras instituições dedicadas à ciência e, muito particularmente, à antropologia no Brasil. Sede do Programa de Pós-Graduação em Antropologia Social da Universidade Federal do Rio de Janeiro, um dos mais relevantes centros de pesquisa e produção de conhecimento em antropologia no Brasil, o Museu Nacional detinha expressivo acervo etnográfico, com destaque para as coleções reunidas por Curt Nimuendajú, conhecido como "pai da etnologia brasileira".

Além disso, congregava coleções diversificadas de objetos de pesquisa científica numa abrangência enciclopédica, desde insetos a fósseis de animais pré-históricos, passando pelo fóssil de Luzia, nossa referência ancestral e que muito nos tem ensinado sobre as origens dos primeiros habitantes em nosso território. A imagem que escolhemos para a capa deste número da revista retrata Kherima, uma jovem que viveu no Egito, entre os séculos I e II da Era Cristã, num período em que o Egito já havia passado para o controle do império romano. Kherima integrava o importante acervo egípcio do Museu Nacional, que foi inteiramente queimado no incêndio de 2018.

O museu mantinha em exposição permanente um conjunto de múmias singulares. Não eram múmias de faraós ou de esferas de poder, mas múmias de personagens ligados ao mundo do sagrado. Além de Kherima, havia a múmia de Hori, um sacerdote de alta hierarquia da $21^{\text {a }}$ Dinastia, a múmia de Sha-Amun-en-su, cantora de Amon em Tebas, da $22^{\text {a }}$ Dinastia, Harsiese, alto funcionário na região tebana, da $26^{\mathrm{a}}$ Dinastia. Parte do importante acervo egípcio do Museu Nacional foi adquirido por D. Pedro I num leilão, em 1826, de um carregamento de peças egípcias oriundas das pilhagens de Belzoni e trazidas por um contrabandista italiano chamado Nicolau Fiengo. A maior parte delas vinha do Vale dos Reis, na antiga Tebas e atual Luxor. D. Pedro I arrematou as 
peças e doou-as ao Museu Real, que havia sido fundado por D. João VI em 1818, que mais tarde se transformaria no Museu Nacional. No período do Segundo Império, D. Pedro II, em sua segunda viagem ao Egito, entre 1876 e 1877, recebeu de presente do quediva Ismail, então soberano local, um esquife lacrado. Dentro do caixão de madeira estucada e colorida havia a múmia de uma cantora-sacerdotisa que entoava cânticos sagrados no templo dedicado ao deus Amon, em Karnak, nos arredores de Tebas (atual Luxor). Essa mulher morreu com cerca de 50 anos durante a XXII dinastia, por volta de 750 a.C. O ataúde de Sha-Amun-en-su, nome que significa "os campos verdejantes de Amon", permaneceu no gabinete de Pedro II no palácio imperial da Quinta da Boa Vista, no Rio de Janeiro, até 1889. Reza a lenda que a múmia era um dos "xodós" do monarca.

Com a proclamação da República, quando o Museu Nacional passou a ocupar o prédio do antigo palácio imperial, a múmia foi incorporada à coleção egípcia. Até o trágico incêndio, o acervo egípcio compunha-se de 700 peças, contendo peças que cobriam praticamente toda a história do Antigo Egito, desde o período Pré-Dinástico (entre 5 mil a 3 mil a.C.) ao período Romano (de 32 a.C. a 395 d.C.). A maior parte era, contudo, do período Faraônico (80\% das peças, de 3 mil a.C. a 32 d.C.), especialmente do Novo Reinado (1550 a 1069 a.C.) e do III Período Intermediário (1069 a 332 a.C.). No acervo, encontravam-se diversos objetos de contexto religioso e funerário. Havia papiros, estátuas de deuses e deusas, estelas funerárias e votivas, shabits (imagens de pessoas para acompanharem o finado no além-vida), amuletos para proteger o corpo mumificado, esquifes, vasos canópicos (para guardar os órgãos do morto) e múmias de gatos, filhotes de crocodilos, íbis, tartarugas e humanos (Pivetta, 2014).

"O acervo egípcio do Museu Nacional era reconhecidamente o maior da América Latina, internacionalmente respeitado. Agora, resta no Brasil o pequeno acervo egípcio do Museu de Arqueologia e Etnologia da USP em São Paulo e as poucas peças originais no Museu Egípcio Rosacruz em Curitiba" (Stella, 2018) A homenagem que fazemos ao Museu Nacional é para nós também uma forma de afirmar nosso mais veemente protesto com relação ao descaso dos poderes públicos com relação aos museus e aos expressivos acervos etnográficos, científicos e históricos reunidos por dezenas de gerações em nosso país.

Queremos reiterar que esta publicação também incentive a contribuição para a campanha "Museu Nacional vive!" trazendo pesquisas e material iconográfico sobre antropologia e museus num esforço de manter vivas na memória 
da população imagens e lembranças de materialidades que arderam para sempre em face do descaso e da falta de investimentos públicos, que infelizmente têm sido uma tendência em nosso país.

O Museu Nacional não era exclusivamente um museu de antropologia, mas detinha um importante acervo etnológico, reunido ao longo desses 200 anos. As coleções eram de diversas procedências, incluindo pesquisas de antropólogos, doações, compras e até mesmo saques e transações coloniais, troféus de guerras entre povos indígenas, presentes de chefes tribais africanos aos governantes portugueses. Neste último caso, estavam os presentes doados em 1811 pelo rei Adandozan, do Daomé, hoje Benin, ao então príncipe regente D. João VI, que geraram uma coleção africana que continha raridades como o trono, a bandeira, objetos de uso pessoal e amuletos diversos. Esses objetos condensavam narrativas sobre relações de poder e cordialidade entre governantes, relações comerciais, deixando entrever personagens obscuros e histórias ainda não desvendadas.

Levando em consideração a pouca sobrevivência de objetos de origem africana desse período, particularmente esses objetos configuravam pistas importantes para estudos e pesquisas sobre a presença africana no Brasil. Os objetos são fontes e referências para a memória e para a história. Alguns são especialmente significativos, como sinalizou Krzysztof Pomian (1984), denominando-os de "semióforos" - objetos dotados de capacidade evocativa, que condensam narrativas e que são elos de ligação entre memórias no tempo e no espaço. Alguns têm “agência”, para usar o conceito de Alfred Gell (1998), e estão investidos de poderes sobre pessoas e seres naturais e sobrenaturais. Outros expressam símbolos reconhecidos culturalmente ou transformam-se em "alegorias", no sentido atribuído por Walter Benjamin (1985), funcionando como pontes entre temporalidades que passaram a não mais se comunicar devido ao caráter abrupto de grandes transformações econômicas, sociais e políticas e seus efeitos nas esferas subjetivas.

A cultura material tem sido um dos focos da antropologia desde os primórdios. No contexto dos pioneiros, coletar objetos em pesquisa de campo configurava uma maneira de atestar ou de exibir a prova material viva dos grupos estudados e de suas diferentes culturas. Muitos museus antropológicos ou etnográficos tornaram-se repositórios de práticas de colecionamento em grande escala e voltadas para esse fim no contexto de uma lógica positivista 
do conhecimento. $\mathrm{O}$ estranhamento com as diferentes alteridades pesquisadas implicaram essa grande empreitada de juntar coisas que representassem ou expressassem as primeiras pesquisas antropológicas. A esse movimento, que teve muita intensidade no século XIX, somou-se um outro: o dos processos coloniais. Ao lado de objetos coletados pelos primeiros antropólogos e pesquisadores dos povos não europeus, foram adicionados objetos retirados pelo saque, a violência e a guerra colonial, que passaram a conviver nas mesmas "reservas técnicas" dos museus. São esses dois tipos de objetos que se inscreveram nas primeiras iniciativas dos departamentos antropológicos nos grandes museus enciclopédicos, um misto de práticas científicas associadas a práticas coloniais. Posteriormente, a prática colecionista dos antropólogos foi aos poucos se refinando e passou a estar cada vez mais ligada aos temas de pesquisas e aos grandes paradigmas científicos. Com a regulação do trânsito dos objetos a partir de agências nacionais e internacionais e, sobretudo, com o desenvolvimento de uma área de estudos e de práticas museológicas, a antropologia beneficiou-se com a criação de departamentos antropológicos mais especializados ou de museus especialmente criados para colecionamento, guarda, pesquisa, difusão e exibição de acervos construídos com base em pesquisas de campo. Todo esse longo processo gerou uma riqueza de propostas museológicas e um conjunto não menos rico de acervos sobre culturas pesquisadas. O campo dos museus que têm em sua base e em suas propostas de colecionamento a ação e a pesquisa de antropólogos é hoje vasto e altamente diversificado, incluindo diferentes temáticas, entre as quais a indígena, a urbana, a de gênero, a da diversidade religiosa, a de diferenças regionais e locais, a de expressões artísticas. Soma-se a essa diversificação o surgimento recente de museus propostos por diferentes povos que passaram a assumir o protagonismo de suas ações e projetos no campo museológico, antropológico e político. Surgiram assim, no final do século XX, museus indígenas, museus de gênero, museus de povos quilombolas ou associados a projetos decoloniais. Outra novidade foram as parcerias crescentes entre antropólogos, museólogos e remanescentes dos povos pesquisados, cujos acervos se encontram preservados em reservas técnicas de instituições museológicas consolidadas.

A antropologia vai aos poucos encontrando no campo dos museus e da museologia fortes aliados para a construção de novos paradigmas voltados para os estudos, as pesquisas, a difusão dos conhecimentos sobre as relações 
sociais e humanas na dinâmica da chamada diversidade cultural. O tema da alteridade é ressignificado a partir da colaboração estreita que os museus passam a ter não apenas com aqueles que estudam e pesquisam as diferentes culturas humanas, mas também com aqueles que as vivenciam ou que se proclamam herdeiros de antigas tradições já desaparecidas e cujos vestígios e traços só podem ser encontrados em reservas técnicas dos museus. Desse modo, os museus e, em especial os museus antropológicos e/ou etnográficos, passaram a desempenhar relevante lugar num mundo cada vez mais interconectado e cujos conhecimentos podem ser compartilhados por grande número de agentes.

A antropologia dos museus como campo específico de estudos e pesquisas surge nesse novo contexto onde o desafio consiste, de um lado, em repensar o lugar do museu, em especial do museu antropológico e/ou etnográfico, e, de outro lado, em refletir de um ponto de vista antropológico sobre o lugar da forma "museu" nas relações sociais e na produção da diversidade cultural no contemporâneo. Uma extensa literatura vem sendo produzida sobre o tema, sinalizando um crescimento significativo da potência dos museus como lugares de estudos, pesquisas e difusão do conhecimento antropológico. Paralelamente, temos assistido a um crescimento do campo da museologia e do patrimônio como um campo de estudos onde não têm sido poucos os antropólogos a se aventurarem em novas e relevantes reflexões. Somando-se a tudo isso, observa-se a entrada massiva de agentes sociais que veem nos museus e nos patrimônios lugares de interlocução e diálogo para a construção de políticas públicas, de afirmação e luta por direitos culturais e congêneres e de relações de interculturalidade. Não é exagero dizer que, de "coisas do passado", os museus passaram a ser hoje lugares de muitas novidades, perplexidades e projetos de futuro para aqueles que acreditam nas práticas da diversidade cultural como importantes patrimônios da espécie humana.

Os artigos apresentados neste número de Horizontes Antropológicos expressam algumas das tendências no campo da antropologia dos museus.

Abrindo o dossiê, apresentamos alguns temas que revelam inquietações e novidades para aqueles que trabalham na área de antropologia dos museus. Adriana Russi e Regina Abreu procuram sistematizar o intenso debate que vem se produzindo em torno do que se convencionou chamar de "museologia colaborativa", processo que envolve o trabalho compartilhado entre profissionais 
de museus, antropólogos e os povos indígenas representados nos museus. O artigo “'Museologia colaborativa': diferentes processos nas relações entre antropólogos, coleções etnográficas e povos indígenas" discorre sobre ações de inclusão e diálogo com remanescentes de povos cujos objetos foram musealizados em diferentes museus. $\mathrm{O}$ artigo focaliza experiências dialógicas, em contextos nacionais e internacionais, que envolvem antropólogos, profissionais de museus, povos indígenas, museus e coleções, apontando para a relevância de práticas colaborativas e simétricas entre aqueles que estudam e representam as diferentes culturas e aqueles que as vivenciam cotidianamente.

Em seguida, trazemos um conjunto extremamente revelador da relação entre museus e projetos políticos em contextos decoloniais. Simone Pondé Vassallo e Luz Stella Rodríguez Cáceres evocam os debates e as diferentes posições envolvidas em torno de um projeto de construção de um museu da escravidão no Rio de Janeiro, em "Conflitos, verdades e política no Museu da Escravidão e da Liberdade no Rio de Janeiro". Fernanda Luíza Teixeira Lima e Aline Vieira de Carvalho apresentam uma experiência de museu cujo objetivo é trazer à tona memórias evocativas de um período recente de ditadura militar no Chile, reiterando a dinâmica entre lembranças e esquecimentos como forma constitutiva dos museus, no artigo "Memórias em construção: o presente e o passado da ditadura militar chilena representados no Museo de la Memoria y los Derechos Humanos".

Na sequência, salientamos dois artigos que fazem uma reflexão antropológica sobre museus e exposições de arte: o primeiro, focalizando a relação entre arte e antropologia em museus de Barcelona, é de autoria de Renata Montechiare e intitula-se "Colecionando arte e antropologia: controvérsias nos museus de Barcelona", enquanto o segundo, de autoria de John Fletcher, apresenta uma etnografia sobre um salão de artes visuais, sob o título "Arte Pará: etnografia e interpretação em um salão de artes visuais na Amazônia". Na mesma linha etnográfica, destacam-se ainda dois artigos. Camila de Fátima Simão de Moura Alcântara descreve o crescente dinamismo da museologia social no artigo "Museus em periferias urbanas brasileiras" e Yasmin Fabris e Ronaldo de Oliveira Corrêa apresentam um estudo de caso sobre uma exposição dedicada à chamada "cultura brasileira" no artigo "(Re)encenando o popular: narrativas sobre a cultura brasileira em uma exposição". O tema da Nova Museologia, movimento de renovação dos processos e estudos museológicos, é acionado por Mariane Aparecida do Nascimento Vieira como elemento explicativo para 
novas propostas de exposição sobre os povos indígenas no contemporâneo. Apresentando uma etnografia sobre a exposição Dja Guata Porã: Rio de Janeiro Indígena, promovida no Rio de Janeiro em maio de 2017 no Museu de Arte do Rio, a autora discute a relação dos povos indígenas com o museu no artigo intitulado “Dja Guata Porã: o rio indígena que desaguou no MAR". Na mesma linha de reflexão sobre a relação entre os povos indígenas e o museu, apresentamos o artigo de Juliana Braz Dias, "Histórias contadas: análise de uma experiência entre os Anishinabe".

Por fim, contemplamos a dimensão histórica da relação entre antropólogos e museus em dois artigos que focalizam momentos seminais na relação entre antropologia e museus: "Um antropólogo no museu: Edgar Roquette-Pinto e o exercício da antropologia no Brasil nas primeiras décadas do século XX", de Rita de Cássia Melo Santos, e "A Exposição Antropológica Brasileira de 1882 e a exibição de índios botocudos: performances de primeiro contato em um caso de zoológico humano brasileiro", de Marina Cavalcante Vieira.

A seção Espaço Aberto contém dois artigos. O primeiro intitula-se "O Museu Nacional: ciência e educação numa história institucional brasileira". Seu autor, Luiz Fernando Dias Duarte é professor titular de Antropologia da UFRJ e foi diretor do Museu Nacional entre 1998 e 2001. No momento, ele é seu diretor adjunto de Assuntos Técnicos. Ele traça um panorama do museu, que em 2018 completou duzentos anos de existência e que, nesse mesmo ano, foi destruído por um incêndio. Sua reflexão é preciosa, pois a história do Museu Nacional reflete a história do país e as vicissitudes pelas quais suas instituições culturais passam.

O segundo artigo, de André Ricardo de Souza, Edin Sued Abumanssur e Jorge Leite Júnior, tem o título "Percursos do Diabo e seus papéis nas igrejas neopentecostais". Baseados numa vasta literatura, seus autores discorrem inicialmente sobre a figura mítica e doutrinária do Diabo no Ocidente cristão, abordando as suas diferentes faces e representações históricas e sua influência e consequência nas práticas de indivíduos, instituições e sociedades. $\mathrm{Na}$ sequência, o texto discorre sobre a diferença de tratamento dado ao Demônio na Igreja Católica e nas igrejas pentecostais, bem como nos meios eruditos e populares. Destaca, no caso do Brasil, o papel crescente que tal figura, enquanto personificação do mal, tem tido nas denominações neopentecostais. Em especial, a análise concentra-se na Igreja Universal do Reino de Deus, que atribui 
aos demônios, identificados com as entidades do panteão afrorreligioso, extraordinária capacidade de influenciarem negativamente as pessoas. Para os autores, nesta igreja o Demônio cumpre um papel político e econômico, pois ela se vale dessa figura para demonizar tanto organizações que considera adversárias nas áreas religiosa, econômica, midiática e política, quanto indivíduos, mesmo políticos da própria igreja, que se envolveram em escândalos no exercício dos seus mandatos.

Por fim, só nos resta desejar boa leitura a todos e todas na certeza de que novos horizontes se descortinam a partir de campos inovadores como o que esta edição apresenta trazendo a antropologia dos museus para o centro do debate.

\section{Referências}

BENJAMIN, W. O narrador: considerações sobre a obra de Nicolai Lescov. In: BENJAMIN, W. Magia e técnica, arte e política: ensaios sobre literatura e história da cultura. São Paulo: Brasiliense, 1985. p. 197-221.

GELL, A. Art and agency: an anthropological theory. Oxford: Oxford University Press, 1998.

PIVETTA, M. O último ato da favorita do imperador. Pesquisa Fapesp, n. 215, jan. 2014. Disponível em: http://revistapesquisa.fapesp.br/2014/01/13/o-ultimo-ato-da-favorita-imperador/. Acesso em: 20 nov. 2018.

POMIAN, K. Coleção. In: ROMANO, R. (org.). Enciclopédia Einaudi. Porto: Imprensa Nacional: Casa da Moeda, 1984. v. 1, p. 51-86.

STELLA, T. H. de T. Importância do acervo egípcio do Museu Nacional na História do Brasil. Vermelho, 6 set. 2018. Disponível em: http://www.vermelho.org.br/noticia/314796-1. Acesso em: 20 nov. 2018. 